\title{
PRODUTIVIDADE DE DUAS CULTIVARES DE MILHO SUBMETIDAS AO TRATAMENTO DE SEMENTES COM BIOESTIMULANTES FERTILIZANTES LÍQUIDOS E Azospirillum sp.
}

\author{
DENIZE CARVALHO MARTINS ${ }^{1}$, IRAN DIAS BORGES ${ }^{2}$, \\ JOSÉ CARLOS CRUZ ${ }^{3}$ e DEA ALÉCIA MARTINS NETTO ${ }^{3}$
}

\begin{abstract}
${ }^{1}$ Universidade Federal de Viçosa, Viçosa, MG, Brasil, denizecarvalhom@yahoo.com.br;
${ }^{2}$ Universidade Federal de São João del-Rei, Sete Lagoas, MG, Brasil, idb@ufsj.edu.br;

${ }^{3}$ Embrapa Milho e Sorgo, Sete Lagoas, MG, Brasil, josecarlos.cruz@embrapa.br, dea.netto@embrapa.br
\end{abstract}

Revista Brasileira de Milho e Sorgo, v.15, n.2, p. 217-228, 2016

\begin{abstract}
RESUMO - Objetivou-se verificar o desempenho agronômico da cultura do milho em função do tratamento de sementes com o inoculante Azo Total ${ }^{\circledR}$ composto de Azospirillum sp., com o bioestimulante Stimulate ${ }^{\circledR}$ e com o fertilizante líquido Cellerate ${ }^{\circledR}$, individualmente e em combinação. O experimento foi conduzido a campo em Sete Lagoas, MG, utilizando-se o delineamento de blocos casualizados com quatro repetições e tratamentos dispostos em esquema fatorial 2x8, sendo duas cultivares de milho (P30F53 e P30F53 YH) e sete tratamentos de sementes mais a testemeunha (T1 $=$ Testemunha; $\mathrm{T} 2=$ Azo Total $^{\circledR} ; \mathrm{T} 3=$ Stimulate $^{\circledR} ; \mathrm{T} 4=$ Cellerate $^{\circledR} ; \mathrm{T} 5=$ Azo Total $^{\circledR}+$ Stimulate $^{\circledR} ; \mathrm{T} 6=$ Azo Total $^{\circledR}+$ Cellerate $^{\circledR} ; \mathrm{T} 7=$ Stimulate $^{\circledR}+$ Cellerate $^{\circledR} ; \mathrm{T} 8=$ Azo Total $^{\circledR}+$ Cellerate $^{\circledR}+$ Stimulate $\left.^{\circledR}\right)$. Para a análise do desempenho agronômico, foram avaliadas as características: altura de planta; altura de espiga; número de espigas; produtividade; diâmetro do colmo; análise foliar; estande final; índice de espiga; e peso de 1.000 grãos. Nas condições de realização deste trabalho, a cultivar P30F53YH proporciona maior produtividade de grãos quando tratada com os produtos Azo Total $^{\circledR}$, Stimulate ${ }^{\circledR}$ e Cellerate ${ }^{\circledR}$. Tratamentos de sementes de milho com os produtos comerciais Azo Total ${ }^{\circledR}$, Stimulate ${ }^{\circledR}$ e Cellerate ${ }^{\circledR}$ não incrementam significativamente a produtividade de grãos. Tratamento de sementes com Azo Total ${ }^{\circledast}$, Stimulate ${ }^{\circledR}$ e Cellerate ${ }^{\circledR}$ não influenciam os teores foliares de nutrientes em plantas de milho.
\end{abstract}

Palavras-chave: Zea mays; produtividade; qualidade fisiológica; tratamento de sementes.

\section{PRODUCTIVITY OF MAIZE CULTIVARS SUBMITTED TO SEED TREATMENT WITH BIOSTIMULANTS LIQUID FERTILIZERS AND Azospirillum sp.}

\begin{abstract}
The objective of this work was to investigate the agronomic performance of maize after the treatment

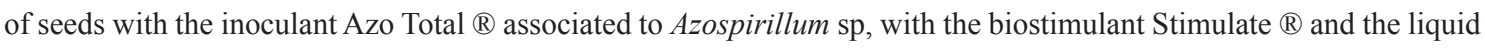
fertilizer Cellerate ${ }^{\circledR}$. The experiment was conducted under field conditions in Sete Lagoas - MG,, using a randomized complete block design ,in a 2x8 factorial design with four replications, with two maize cultivars (P30F53 and P30F53 $\mathrm{YH})$ and seven seed treatments and one control $\left(\mathrm{T} 1=\right.$ Control; $\mathrm{T} 2=$ Azo Total ${ }^{\circledR} ; \mathrm{T} 3=$ Stimulate ${ }^{\circledR}, \mathrm{T} 4=$ Cellerate ${ }^{\circledR}$,

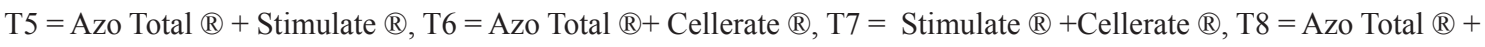
Cellerate ${ }^{\circledR}+$ Stimulate $(\mathbb{B})$.For the analysis of agronomic performance were evaluated the characteristics plant height, ear height, number of ears, productivity, stem diameter, leaf analysis, final stand, ear index and 1000 grain weight. The cultivar P30F53YH showed higher grain yield when treated with Azo Total ${ }^{\circledR}$, Stimulate ${ }^{\circledR}$ and Cellerate ${ }^{\circledR}$. Treatment

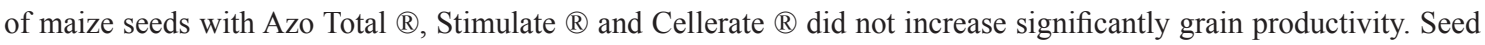
treatment with Azo Total $\AA$, Stimulate $\AA$ and Cellerate $\AA$ did not affect the concentration of foliar nutrients in maize plants .
\end{abstract}

Key words: Zea mays; productivity; physiological quality; seed treatment.

Versão impressa ISSN 1676-689X / Versão on line ISSN 1980-6477

http://www.rbms.cnpms.embrapa.br 
Na busca pela elevação dos níveis atuais de produtividade e pela redução nos custos de produção do milho no Brasil, novas tecnologias vêm sendo incorporadas aos sistemas de produção. Dentre essas, a utilização de biorreguladores, fertilizantes líquidos e inoculantes a base Azospirillum sp., aplicados via tratamento de sementes, são consideradas estratégias agronômicas promissoras para o incremento da produtividade e vêm ganhando espaço e importância nos últimos anos.

As bactérias do gênero Azospirillum atuam diretamente na fixação biológica de nitrogênio (Ashraf et al., 2011) e são capazes de assimilar o $\mathrm{N}_{2}$ atmosférico e convertê-lo à forma assimilável $\left(\mathrm{NH}_{3}\right)$, cujo processo é denominado fixação biológica de nitrogênio (FBN). Na agricultura sustentável, a fixação biológica de $\mathrm{N}_{2}$ é uma importante forma de entrada de nitrogênio no sistema solo-planta (Sharma et al., 2005).

$\mathrm{O} \mathrm{N}$ fornecido pelo processo de fixação biológica é menos propenso a lixiviação e volatilização, já que é utilizado in situ. Sendo assim, o processo biológico é uma alternativa barata, limpa e sustentável para o fornecimento de $\mathrm{N}$ na agricultura comercial (Huergo, 2006).

Ao contrário das leguminosas, a inoculação de não leguminosas não consegue suprir totalmente as necessidades das plantas em nitrogênio (Hungria, 2011).

Os resultados de pesquisas com a utilização de bactérias diazotróficas no desempenho agronômico do milho são variados. Os efeitos positivos da interação entre Azospirillum sp. e milho, tais como aumentos da produção de matéria seca, rendimento de grãos e o acúmulo de nitrogênio em plantas inoculadas, foram relatados por Hungria et al. (2010). Dotto et al. (2010) verificaram que a bactéria não influenciou a produtividade do híbrido de milho inoculado.
Sangoi et al. (2015) concluíram que o tratamento de sementes com Azospirillum não contribuiu para aumentar o rendimento de grãos do milho.

Os bioestimulantes também têm apresentado crescente uso como técnica agronômica para melhorar a produtividade de diversas culturas. Os hormônios contidos nos bioestimulantes são moléculas sinalizadoras, naturalmente presentes nas plantas em concentrações pequenas, sendo responsáveis por efeitos marcantes no desenvolvimento vegetal (Taiz \& Zeiger, 2004).

O Stimulate ${ }^{\circledR}$ é um bioestimulante da Stoller Interprises Inc., contendo reguladores vegetais e traços de sais minerais quelatizados. Seus reguladores vegetais constituintes são ácido índolbutírico (auxina) 0,005\%, cinetina (citocinina) 0,009\% e ácido giberélico (giberelina) 0,005\%. Resultados obtidos em pesquisas têm sido contraditórios em relação à utilização do bioestimulante Stimulate ${ }^{\circledR}$. Em milho, não houve melhoria da qualidade de sementes quando elas foram submetidas a tratamento com bioestimulantes (Silva et al., 2008).

$\mathrm{O}$ uso de fertilizantes líquidos contendo micronutrientes também vem ganhando importância na agricultura. Eles são aderidos na semente para minimizar problemas de deficiência de micronutrientes durante os processos de germinação, desenvolvimento e produção de grãos.

A disponibilidade de produtos comerciais contendo micronutrientes tem aumentado nos últimos anos e existem resultados experimentais mostrando grande variabilidade de resposta à sua aplicação (Ceretta et al., 2005). O tratamento de sementes com micronutrientes apresenta vantagens, tais como: melhor uniformidade de aplicação; bom aproveitamento pela planta; e, principalmente, redução dos custos de aplicação (Luchese et al., 2004). 
O tratamento de sementes com micronutrientes tem apresentado resultados significativos, principalmente em regiões que adotam elevados níveis de tecnologia e manejo nas culturas (Ávila et al., 2006).

A resposta à aplicação de micronutrientes, bioestimulantes e Azospririllum sp. é muito variável, mas o aumento da produtividade que ocorre em alguns casos e, consequentemente, a diminuição do custo relativo de produção têm motivado produtores a utilizá-los, principalmente na cultura do milho.

Existe uma grande evolução no nível tecnológico da produção de milho no Brasil, mas maximização da produtividade só faz sentido quando associada à otimização do uso de insumos, atendendo aos critérios de sustentabilidade e maior rentabilidade (Cruz et al., 2013).

Apesar de haver recomendação de vários produtos no mercado para uso em sementes de milho, o uso desses produtos associados pode afetar a produtividade do milho. Assim, objetivou-se, com este trabalho, avaliar o desempenho de genótipos de milho submetidos a diferentes tratamentos de sementes com o uso do bioestimulante Stimulate ${ }^{\circledR}$, o fertilizante líquido Cellerate ${ }^{\circledR}$ e o inoculante composto de Azospirillum sp. Azo Total ${ }^{\circledR}$ e obter melhor manejo desses produtos de forma a ter uma recomendação adequada.

\section{Material e Métodos}

O trabalho foi conduzido na safra de primavera-verão 2012/2013 para a avaliação de genótipos de milho em diferentes tratamentos de sementes com o fertilizante líquido Cellerate ${ }^{\circledR}$, o bioestimulante Stimulate ${ }^{\circledR}$ e o inoculante composto de Azospirillum sp. Azo Total ${ }^{\circledR}$.

$\mathrm{O}$ experimento foi conduzido em campo em área experimental do CNPMS, Centro Nacional de
Pesquisa Milho e Sorgo, localizado em Sete Lagoas, MG, sob sistema de plantio semidireto e com irrigação suplementar do tipo aspersão convencional, quando necessária. A área experimental está localizada a $12 \mathrm{~km}$ da cidade de Sete Lagoas, na região Central de Minas Gerais, com coordenadas geográficas $19^{\circ} 28^{\prime}$ 36 " de latitude Sul e 44 11 ' 53" de longitude Oeste, com altitude de $769 \mathrm{~m}$. O solo da área experimental é um latossolo vermelho distroférrico e o clima, segundo Köppen, é do tipo AW (tropical estacional de savana, inverno seco), temperatura média anual de 22,1 ${ }^{\circ} \mathrm{C}$ e precipitação média anual $1.340 \mathrm{~mm}$.

Foram utilizados dois híbridos simples de milho, P30F53 e P30F53 YH, recomendados para as condições edafoclimáticas da região Central de Minas. Os dois genótipos de milho foram submetidos a diferentes tratamentos de sementes. O delineamento utilizado foi o de blocos casualizados, com quatro repetições.

Os tratamentos foram dispostos em esquema fatorial $2 \times 8$, sendo os dois híbridos e os sete tratamentos de sementes e a testemunha, descritos: $\mathrm{T} 1=$ Testemunha; $\mathrm{T} 2=$ Azo Tota $^{\circledR} ;$; $3=$ Stimulate $^{\circledR} ;$ T4 $=$ Cellerate $^{\circledR} ;$ T5 $=$ Azo Total $^{\circledR}+$ Stimulate $^{\circledR} ;$ T6 $=$ Azo Total $^{\circledR}+$ Cellerate $^{\circledR} ; \mathrm{T} 7=$ Stimulate $^{\circledR}+$ Cellerate $^{\circledR} ; \mathrm{T} 8$ $=$ Azo Total ${ }^{\circledR}+$ Cellerate $^{\circledR}+$ Stimulate $^{\circledR}$.

As sementes de milho foram tratadas com o Azo Total ${ }^{\circledR}$ na dosagem de $1000 \mathrm{~mL} / 60.000$ sementes, o bioestimulante Stimulate ${ }^{\circledR}$ na dosagem de 12,5 $\mathrm{mL} \mathrm{kg}^{-1}$ de sementes e parte com o fertilizante Cellerate ${ }^{\circledR}$ na dosagem de $17,5 \mathrm{~mL} \mathrm{~kg}^{-1}$ de sementes. $\mathrm{O}$ tratamento com os produtos foi realizado na pré-semeadura, utilizando-se as mesmas dosagens para todos os tratamentos.

A correção do solo e as adubações de semeadura e de cobertura foram realizadas considerando a análise química do solo (Tabela 1). 
Tabela 1. Resultados da análise de amostras de solo $(0-20 \mathrm{~cm})$ da área do experimento antes da implantação do experimento. Sete Lagoas, MG, 2014.

\begin{tabular}{ccccccccccc}
\hline $\mathrm{Ph}$ & $\mathrm{H}+\mathrm{AL}$ & $\mathrm{P}$ & $\begin{array}{c}\text { CARBONO } \\
\text { TOTAL }\end{array}$ & $\mathrm{Al}$ & $\mathrm{Ca}$ & $\mathrm{Mg}$ & $\mathrm{K}$ & $\mathrm{SB}$ & $\mathrm{CTC}$ & $\mathrm{V}$ \\
\hline$\left(\mathrm{H}_{2} \mathrm{O}\right)$ & $\left(\mathrm{cmolc} / \mathrm{cm}^{3}\right)$ & $\left(\mathrm{mg} / \mathrm{dm}^{3}\right)$ & $(\%)$ & $\left(\mathrm{cmolc}^{2} / \mathrm{dm}^{3}\right)$ & $\left(\mathrm{cmolc}^{2} \mathrm{dm}^{3}\right)$ & $\left(\mathrm{cmolc} / \mathrm{dm}^{3}\right)$ & $\left(\mathrm{mg} / \mathrm{dm}^{3}\right)$ & $\left(\mathrm{cmolc}^{3} \mathrm{dm}^{3}\right)$ & $\left(\mathrm{cmolc}^{2} \mathrm{dm}^{3}\right)$ & $(\%)$ \\
6,3 & 1,42 & 11,25 & 1,69 & $*$ & 4,07 & 0,50 & 94 & 4,82 & 6,24 & 77 \\
\hline $\mathrm{Cu}$ & $\mathrm{Fe}$ & $\mathrm{Mn}$ & $\mathrm{Zn}$ & & & & & & & \\
\hline$\left(\mathrm{mg} / \mathrm{dm}^{3}\right)$ & $\left(\mathrm{mg} / \mathrm{dm}^{3}\right)$ & $\left(\mathrm{mg} / \mathrm{dm}^{3}\right)$ & $(\mathrm{mg} / \mathrm{dm} 3)$ & & & & & & \\
0,93 & 25,92 & 12,30 & 3,81 & & & & & & \\
\hline
\end{tabular}

Métodos utilizados: $\mathrm{pH}$-> $\mathrm{H}_{2} \mathrm{O}(1: 2,5) / \mathrm{Al}, \mathrm{Ca}, \mathrm{Mg}->\mathrm{KCl} 1 \mathrm{~N} / \mathrm{K}, \mathrm{P}->$ Mehlich $\left(\mathrm{HCl} 0,05 \mathrm{~N}+\mathrm{H}_{2} \mathrm{SO}_{4} 0,025 \mathrm{~N}\right)$.

A semeadura foi realizada na última quinzena do mês de outubro de 2012. Cada parcela foi constituída de cinco linhas de $6 \mathrm{~m}$ de comprimento, espaçadas $0,5 \mathrm{~m}$ entrelinhas, considerando a densidade de 60.000 plantas ha $^{-1}$, sendo consideradas como área útil as três linhas centrais. Foram distribuídas seis sementes por metro linear, realizando-se o desbaste 30 dias após a semeadura, deixando-se três plantas por metro linear.

Todos os tratamentos receberam a mesma adubação de plantio. A adubação de base foi realizada com 350 kg.ha-1 de NPK 8-28-16 e $100 \mathrm{~kg} \mathrm{ha}^{-1}$ de N em cobertura. A adubação de cobertura foi realizada de acordo com o manejo convencional da cultura, aos 40 dias após a semeadura.

Irrigação complementar foi realizada por meio de aspersão convencional, sendo o manejo realizado utilizando-se dados da estação climatológica do CNPMS/Embrapa. Os controles de plantas daninhas, pragas e doenças foram feitos sempre que necessários, mediante monitoramento constante.

No estádio 5 (florescimento), foram avaliadas as características agronômicas altura de plantas e diâmetro do colmo e, no estádio 6 (grãos leitosos), a altura de espiga, utilizando-se 10 plantas por parcela útil. No estádio de florescimento, foram ainda coletadas o terço médio de 30 folhas por parcela da base da espiga para análise foliar. E, na colheita, foram determinados número de espigas, estande final, índice de espigamento (relação número de plantas/número de espigas), peso de 1.000 grãos e produtividade de grãos $\left(\mathrm{kg} \mathrm{ha}^{-1}\right)$ a $13 \%$ de umidade em cada parcela útil.

Os resultados foram submetidos à análise de variância individualmente e, quando ocorreram diferenças significativas identificadas pelo teste $\mathrm{F}(\mathrm{P}<$ 0,05), foram aplicados testes de médias com o auxílio do programa estatístico Sisvar (Ferreira, 2011).

\section{Resultados e discussão}

O resumo da análise de variância para os resultados referentes às características agronômicas estande final, número de espigas, índice de espigamento, peso de 1.000 grãos, produtividade, altura de plantas, altura de espiga e diâmetro do colmo estão apresentados na Tabela 2.

Para todas as características avaliadas, não 
houve efeito significativo em função dos tratamentos de sementes utilizados. $\mathrm{O}$ fato da falta de resposta positiva, em relação aos tratamentos de sementes com os produtos comerciais analisados, pode ser devido a vários fatores. Para Didonet et al. (2000), a inoculação de bactérias diazotróficas em sementes deve levar em consideração que estas estão amplamente distribuídas nos solos; portanto, a inoculação a base de bactérias do gênero Azospirillum deve competir satisfatoriamente com as bactérias diazotróficas nativas e com microflora do solo, dificultando a expressão do efeito positivo dessa prática. Isso pode justificar total ou parcialmente os resultados obtidos. Contudo, no presente trabalho, objetivou-se a avaliação de características fitotécnicas, não contemplando a mensuração da distribuição das bactérias no solo, bem como a capacidade competitiva dessas e da microflora do solo.

Segundo Silva et al. (2007), a capacidade competitiva das bactérias diazotróficas com outras é alta somente quando as condições são de baixa disponibilidade de N no ambiente. A adição de fertilizante nitrogenado no solo pode influenciar a diminuição de microrganismos diazotróficos (Repke et al., 2013).

Com o nitrogênio disponível na forma mineral, o complexo da nitrogenase não é sintetizado e as plantas passam a utilizar o nitrogênio disponível. Roesch et al. (2006) também verificaram que a colonização de raízes de plantas de milho por bactérias diazotróficas foi inibida por altas doses de nitrogênio durante os primeiros estádios de crescimento. Entretanto, Cavallet et al. (2000), em condições de semeadura direta em latossolo vermelho eutroférrico de fertilidade média a alta, verificaram aumentos de produtividade de 17\% com o uso da bactéria Azospirillum sp. em plantas de milho. Segundo Quadros et al. (2014), o clima e o tipo de solo podem interferir na adaptação das bactérias inoculadas, podendo gerar variações nos resultados de inoculação, dependendo da localização geográfica.

Apesar de avanços da pesquisa, resultados obtidos em ensaios de campo quanto à eficácia agronômica de inoculantes a base de Azospirillum não são consistentes (Hungria et al., 2010). Isso se evidencia neste trabalho. A sua adoção como técnica complementar à adubação de $\mathrm{N}$ ainda é questionável. São necessários mais estudos sobre a eficiência das bactérias do gênero Azospirillum sobre os rendimentos na cultura do milho, assim como os demais produtos Stimulate ${ }^{\circledR}$ e Cellerate ${ }^{\circledR}$. Trabalhos como esses, que visam ao emprego de diversos produtos no tratamento de sementes de forma associada, são importantes, uma vez que a maioria das respostas que se têm até o momento é obtida de forma isolada.

Ferreira et al. (2007) verificaram que o tratamento das sementes de milho com o bioestimulante Stimulate ${ }^{\circledR}$ e com o fertilizante Cellerate ${ }^{\circledR}$ não afeta a produtividade de grãos. A ausência de resposta significativa quanto à aplicação do Cellerate $\AA$ na produção milho pode ter ocorrido devido à alta disponibilidade de zinco no solo 3,81 $\mathrm{mg} \mathrm{dm}^{-3}$ (Tabela 1). E devido ao teor de molibdênio estar no solo em quantia supostamente suficiente para possibilitar o crescimento e o desenvolvimento normal das plantas.

Segundo Santos (2008), a ausência de resposta da aplicação de Mo em sementes de milho ocorreu devido ao suprimento desse micronutriente pelas sementes ser suficiente para ativar o metabolismo da planta, atuando como cofator na atividade do nitrato redutase, porém não interferindo na produtividade da cultura. Ávila et al. (2006) observaram que o tratamento das sementes de milho com micronutrientes não apresentou resultados satisfatórios em aumentar 
a produtividade de sementes de todos os híbridos avaliados.

Considerando as condições em que o experimento foi desenvolvido, a aplicação dos produtos utilizados Cellerate ${ }^{\circledR}$, Stimulate ${ }^{\circledR}$ e Azospirillum sp. não apresentou vantagens para a cultura, representando ainda maior custo para o produtor.

Uma possível razão para a ausência de resposta para aplicação de Cellerate ${ }^{\circledR}$, Stimulate ${ }^{\circledR}$ e Azospirillum sp. em sementes de milho pode estar relacionada aos teores dos nutrientes presentes no solo no início do experimento e às boas condições do solo de forma geral (Tabela 2). Para as características número de espigas, índice de espigamento e produtividade, a cultivar 30F53YH apresentou melhores resultados que a cultivar 30F53 (Tabela 3). Provavelmente, a maior produtividade da cultivar 30F53YH ocorreu em razão do maior índice de espigamento e do maior núme- ro de espigas desta em relação à cultivar 30F53. A produtividade de grãos de milho é determinada pela densidade de plantas, prolificidade ou número de espigas por planta, número médio de fileiras de grãos por espiga, número médio de grãos por fileira e massa média do grão (Balbinot Júnior et al., 2005).

Esse maior índice de espigamento da cultivar 30F53YH em relação à cultivar 30F53 pode ser devido à ocorrência do ataque de lagartas na fase inicial de condução do experimento. Apesar de não ser esperado, houve um pequeno ataque de lagartas para a 30F53YH. Esse ataque foi mais severo na cultivar 30F53, o que pode ter influenciado o índice de espigamento, pois a formação da espiga da planta de milho começa no primeiro estádio de desenvolvimento do milho. Assim, qualquer tipo de estresse, biótico ou abiótico, nessa fase inicial comprometeria o tamanho de espigas.

Tabela 2. Resumo da análise de variância para os resultados das características agronômicas estande final (EF), número de espigas (NE), índice de espigamento (IE), peso de 1.000 grãos (P), altura (A), altura da espiga (ESP), diâmetro do colmo (DC) e produtividade (PROD) considerando duas cultivares de milho submetidas a diferentes tratamentos de sementes. Sete Lagoas, MG, 2014.

\begin{tabular}{|c|c|c|c|c|c|c|c|c|c|}
\hline \multicolumn{10}{|c|}{ QM } \\
\hline FV & GL & $\begin{array}{c}\text { EF } \\
\text { (pl parcela) }\end{array}$ & $\begin{array}{l}\mathrm{NE} \\
\text { (parcela) }\end{array}$ & $\begin{array}{c}\text { IE } \\
\text { (pl parcela) }\end{array}$ & $\begin{array}{c}P \\
(g)\end{array}$ & $\begin{array}{c}\text { A } \\
(\mathrm{m})\end{array}$ & $\begin{array}{l}\text { ESP } \\
(\mathrm{m})\end{array}$ & $\begin{array}{l}\mathrm{DC} \\
(\mathrm{cm})\end{array}$ & $\begin{array}{l}\text { PROD } \\
\left(\mathrm{t} \mathrm{ha}^{-1}\right)\end{array}$ \\
\hline Bloco & 3 & $1,375^{\mathrm{n} . \mathrm{s}}$ & $4,848^{\mathrm{n} . \mathrm{s}}$ & $0,001^{\mathrm{n} . \mathrm{s}}$ & $2365,427^{\text {n.s }}$ & $0,004^{\text {n.s }}$ & $0,005^{\text {n.s }}$ & $0,065^{\mathrm{n} . \mathrm{s}}$ & $0,900^{\text {n.s }}$ \\
\hline Trat. & 7 & $6,392^{\text {n.s }}$ & $15,962^{\mathrm{n} . \mathrm{s}}$ & $0,006^{\mathrm{n} . \mathrm{s}}$ & $1170,363^{\mathrm{n} . \mathrm{s}}$ & $0,001^{\text {n.s }}$ & $0,001^{n . s}$ & $0,003^{\mathrm{n} . \mathrm{s}}$ & $0,344^{\text {n.s }}$ \\
\hline Cult. & 1 & $6,250^{\text {n.s }}$ & $221,265 * *$ & $0,055 * *$ & $199,021^{\mathrm{n} . \mathrm{s}}$ & $0,153 * *$ & $0,093 * *$ & $0,265^{* *}$ & $3,925^{*}$ \\
\hline $\mathrm{T} \times \mathrm{C}$ & 7 & $6,750^{\mathrm{n} . \mathrm{s}}$ & $18,729^{\mathrm{n} . \mathrm{s}}$ & $0,004^{\mathrm{n} . \mathrm{s}}$ & $677,465^{\mathrm{n} . \mathrm{s}}$ & $0,004^{\text {n.s }}$ & $0,003^{\mathrm{n} . \mathrm{s}}$ & $0,007^{\text {n.s }}$ & $0,128^{\mathrm{n} . \mathrm{s}}$ \\
\hline Erro & 45 & 4,297 & 13,582 & 0,005 & 639,943 & 0,004 & 0,002 & 0,012 & 0,506 \\
\hline Total & 63 & & & & & & & & \\
\hline Média & & 54,312 & 61,453 & 1,1323 & 246,226 & 2,106 & 1,088 & 2,376 & 9,002 \\
\hline CV \% & & 3,82 & 6,00 & 6,25 & 10,27 & 2,98 & 4,2 & 4,67 & 7,9 \\
\hline
\end{tabular}

$* *(\mathrm{P} \leq 0,01) ; *(\mathrm{P} \leq 0,05){ }_{\text {n.s }}$ não significativo. 
A cultivar $30 \mathrm{~F} 53 \mathrm{YH}$ apresentou maior altura de plantas, altura de espigas e diâmetro do colmo em relação à cultivar 30F53. Provavelmente, isso também se justifica por ter a cultivar transgênica sofrido menos com o ataque de pragas durante o ciclo. Contudo, é de se esperar que a maior altura de plantas de milho se reflita numa maior altura de inserção de espiga.

Embora não tenham sido encontradas diferenças significativas para a produtividade das cultivares de milho em função dos tratamentos de sementes, observa-se na Tabela 4 que, quando as cultivares de milho receberam tratamento de sementes, houve um superioridade da maioria dos tratamentos utilizados em relação à testemunha, sendo que, para as duas cultivares, o tratamento Stimulate ${ }^{\circledR}+$ Cellerate ${ }^{\circledR}$ apresentou melhores resultados em relação aos demais.

O resumo da análise de variância para os resultados referentes a análise foliar para os teores de nitrogênio, potássio, cálcio, magnésio, enxofre, cobre, ferro, manganês e zinco está apresentado na Tabela 5 .

As quantidades de nutrientes extraídas pelas plantas de milho dependem de fatores como produtividade, clima, fertilidade do solo, adubação e tratos culturais, dentre outros (Borges, 2006). Não foi verificado efeito significativo dos fatores analisados,

Tabela 3. Número de espigas (NE), índice de espigamento (IE), produtividade (PROD), altura da planta (AP), altura da espiga (AE), diâmetro do colmo (DC) de duas cultivares de híbridos de milho tratadas com diferentes produtos. Sete Lagoas, MG, 2014.

\begin{tabular}{cllcccc}
\hline Cultivar & NE & IE & PROD & $\begin{array}{c}\text { AP } \\
(\mathrm{m})\end{array}$ & $\begin{array}{c}\text { AE } \\
(\mathrm{m})\end{array}$ & $\begin{array}{c}\text { DC } \\
(\mathrm{cm})\end{array}$ \\
\hline 30F53 & $59,59 \mathrm{~b}$ & $1,10 \mathrm{~b}$ & $8,75 \mathrm{~b}$ & $2,05 \mathrm{~b}$ & $1.05 \mathrm{~b}$ & $2,31 \mathrm{~b}$ \\
$30 \mathrm{~F} 53 \mathrm{YH}$ & $63.31 \mathrm{a}$ & $1.16 \mathrm{a}$ & $9,25 \mathrm{a}$ & $2,15 \mathrm{a}$ & $1.12 \mathrm{a}$ & $2,44 \mathrm{a}$ \\
\hline
\end{tabular}

Tabela 4. Valores médios da produtividade de duas cultivares de milho e suas respectivas porcentagens de variação em relação à média da testemunha submetidas a diferentes tratamentos de sementes. Sete Lagoas, MG, 2014.

\begin{tabular}{lcccc}
\hline \multirow{2}{*}{ Tratamentos } & \multicolumn{3}{c}{ Produtividade Cultivares } \\
\cline { 2 - 5 } & $30 \mathrm{F53}$ & $(\%)$ & $30 \mathrm{F53}$ YH & $(\%)$ \\
\hline Testemunha & 8,50 & - & 9,10 & - \\
Azo Total $^{\circledR}$ & 8,85 & 4,12 & 9,75 & 7,14 \\
Stimulate $^{\circledR}$ & 9,00 & 5,88 & 9,35 & 2,75 \\
Cellerate $^{\circledR}$ & 8,90 & 4,71 & 8,95 & $-1,65$ \\
Azo Total $^{\circledR}+$ Stimulate $^{\circledR}$ & 8,45 & $-0,59$ & 9,00 & $-1,10$ \\
Azo Total $^{\circledR}+$ Cellerate $^{\circledR}$ & 9,00 & 5,88 & 9,10 & 0,00 \\
Stimulate $^{\circledR}+$ Cellerate $^{\circledR}$ & 9,00 & 5,88 & 10,00 & 9,89 \\
Azo Total $^{\circledR}+$ Stimulate $^{\circledR}+$ Cellerate $^{\circledR}$ & 8,60 & 1,18 & 9,50 & 4,40 \\
\hline
\end{tabular}


Tabela 5. Resumo da análise de variância para os teores foliares dos nutrientes nitrogênio $(\mathrm{N})$, fósforo $(\mathrm{P})$, potássio $(\mathrm{K})$, cálcio $(\mathrm{Ca})$, magnésio $(\mathrm{Mg})$, enxofre $(\mathrm{S})$, cobre $(\mathrm{Cu})$, ferro $(\mathrm{Fe})$, manganês $(\mathrm{Mn})$ e zinco $(\mathrm{Zn})$ de duas cultivares de milho tratadas com diferentes produtos. Sete Lagoas, MG, 2014.

\begin{tabular}{|c|c|c|c|c|c|c|c|c|c|c|c|}
\hline \multirow[b]{2}{*}{ FV } & \multirow[b]{2}{*}{ GL } & \multicolumn{10}{|c|}{ QM } \\
\hline & & $\mathrm{N}$ & $\mathrm{P}$ & $\mathrm{K}$ & $\mathrm{Ca}$ & $\mathrm{Mg}$ & $\mathrm{S}$ & $\mathrm{Cu}$ & $\mathrm{Fe}$ & $\mathrm{Mn}$ & $\mathrm{Zn}$ \\
\hline Bloco & 3 & $0,001^{\mathrm{n} . \mathrm{s}}$ & $0,004^{\mathrm{n} . \mathrm{s}}$ & $109,32^{* *}$ & $0,115^{\mathrm{n} . \mathrm{s}}$ & $0,265^{\text {n.s }}$ & $0,009^{\text {n.s }}$ & s $0,337^{\text {n.s }}$ & s $9017,429^{* *}$ & $13,47^{n . s}$ & $3,93^{\mathrm{n} . \mathrm{s}}$ \\
\hline Trat. & 7 & $0,001^{\mathrm{n} . \mathrm{s}}$ & $0,024 \mathrm{n} . \mathrm{s}$ & $5,58^{\text {n.s }}$ & $0,097^{\mathrm{n} . \mathrm{s}}$ & s $0,240^{\text {n.s }}$ & ${ }^{\mathrm{s}} 0,009^{\mathrm{n} . \mathrm{s}}$ & s $0,578^{\text {n.s }}$ & $. s \quad 920,349^{\text {n.s }}$ & $5,14^{\text {n.s }}$ & $1,50^{\mathrm{n} . \mathrm{s}}$ \\
\hline Cult. & 1 & $0,000^{\text {n.s }}$ & $0,001^{\mathrm{n} . \mathrm{s}}$ & $2,14^{\text {n.s }}$ & $0,069^{\mathrm{n} . \mathrm{s}}$ & $0,214^{\mathrm{n} . \mathrm{s}}$ & $0,000^{\mathrm{n} . \mathrm{s}}$ & $0,439^{\text {n.s }}$ & $74,261^{\mathrm{n} . \mathrm{s}}$ & $10,24^{\text {n.s }}$ & $2,13^{\mathrm{n} . \mathrm{s}}$ \\
\hline $\mathrm{T} \times \mathrm{C}$ & 7 & $0,001^{\text {n.s }}$ & $0,042^{\mathrm{n} \cdot \mathrm{s}}$ & $8,049^{\text {n.s }}$ & $0,041^{\mathrm{n} . \mathrm{s}}$ & $0,189^{\mathrm{n} . \mathrm{s}}$ & $0,010^{\text {n.s }}$ & $0,418^{\mathrm{n} . \mathrm{s}}$ & $717,294^{\mathrm{n} . \mathrm{s}}$ & $4,577^{\mathrm{n} . \mathrm{s}}$ & $1,609^{\mathrm{n} \cdot \mathrm{s}}$ \\
\hline Erro & 45 & 0,001 & 0,038 & 8,830 & 0,089 & 0,217 & 0,008 & 0,929 & 842,557 & 10,549 & 3,919 \\
\hline Total & 63 & & & & & & & & & & \\
\hline \multicolumn{12}{|l|}{ Média } \\
\hline Geral & & 4,00 & 3,04 & 244,19 & 3,91 & 1,41 & 2,04 & 10,69 & 170,30 & 38,23 & 12,50 \\
\hline $\mathrm{CV} \%$ & & 0,31 & 6,43 & 12,28 & 7,67 & 33,02 & 0,42 & 9,02 & 17,04 & 8,5 & 15,84 \\
\hline
\end{tabular}

tratamentos e cultivares, e nem da interação entre eles sobre os teores médios foliares dos nutrientes avaliados.

Outros autores avaliaram anteriormente os valores médios dos teores foliares de nutrientes em plantas de milho obtendo resultados, de maneira geral, muito semelhantes aos obtidos no presente trabalho (Tabela 6).

O teor de nitrogênio nas folhas das plantas de milho é influenciado pela adubação nitrogenada. A alta disponibilidade de nitrogênio no solo da área experimental, talvez devido ao histórico de plantios consecutivos de milho por vários anos e à adequada fertilização com $\mathrm{N}$ no plantio e em cobertura, pode ter contribuído para a elevada extração desse nutriente pela planta (4\%), valor este que se destaca em relação a outros trabalhos (Tabela 6).

De acordo com Ferreira et al. (2001), em trabalho com milho adubado com nitrogênio, molibdênio e zinco, o teordenitrogênio foliarencontradoaos 45 eaos 65 diasapós a emergência, necessário para garantir $90 \%$ da produção máxima de grãos, é de 2,73\% e 2,00\%, respectivamente.

Os acúmulos de fósforo, cálcio e enxofre estão dentro dos teores considerados ideais para a cultura e semelhantes aos valores obtidos em outros trabalhos (Tabela 6). Os acúmulos de potássio observados, assim como para o N, são superiores aos obtidos pelos demais autores (tabela 6), enfatizando as 
Tabela 6. Teores médios foliares de nitrogênio $(\mathrm{N})$, em porcentagem, de fósforo $(\mathrm{P})$, potássio $(\mathrm{K})$, cálcio $(\mathrm{Ca})$, magnésio $(\mathrm{Mg})$ e enxofre $(\mathrm{S})$, em $\mathrm{g} / \mathrm{kg}$, e de cobre $(\mathrm{Cu})$, ferro $(\mathrm{Fe})$, manganês $(\mathrm{Mn})$ e zinco $(\mathrm{Zn})$, em mg kg-1, obtidos em plantas de milho por quatro autores em trabalhos conduzidos no Brasil. Sete Lagoas, MG, 2014.

\begin{tabular}{lcccccccccc}
\hline \multirow{2}{*}{ Autores } & $\mathrm{N}$ & $\mathrm{P}$ & $\mathrm{K}$ & $\mathrm{Ca}$ & $\mathrm{Mg}$ & $\mathrm{S}$ & $\mathrm{Cu}$ & $\mathrm{Fe}$ & $\mathrm{Mn}$ & $\mathrm{Zn}$ \\
\cline { 2 - 9 } & $\%$ & $\left(\mathrm{~g} \mathrm{~kg}^{-1}\right)$ & $\left(\mathrm{g} \mathrm{kg}^{-1}\right)$ & $\left(\mathrm{g} \mathrm{kg}^{-1}\right)$ & $\left(\mathrm{g} \mathrm{kg}^{-1}\right)$ & $\left(\mathrm{g} \mathrm{kg}^{-1}\right)$ & $\left(\mathrm{mg} \mathrm{kg}^{-1}\right)$ & $\left(\mathrm{mg} \mathrm{kg}^{-1}\right)$ & $\left(\mathrm{mg} \mathrm{kg}^{-1}\right)$ & $\left(\mathrm{mg} \mathrm{kg}^{-1}\right)$ \\
\hline Martinnes & $2,75-$ & $2,50-$ & $17,5-$ & $2,50-$ & $2,50-$ & $1,00-$ & $6-20$ & $20-250$ & $20-150$ & $20-70$ \\
et al. & 3,25 & 3,50 & 22,5 & 4,00 & 4,00 & 2,00 & & & & \\
$(1999)^{(1)}$ & & & & & & & & & & \\
\hline $\begin{array}{l}\text { Martins } \\
(2014)^{(2)}\end{array}$ & 4 & 3,03 & 24,18 & 3,92 & 1,42 & 2,00 & 10,21 & 170,31 & 38,25 & 12,5 \\
\hline Ferreira et & 2 & 1,6 & 13,3 & 6,0 & 3,7 & 1,1 & 10,57 & 116,17 & 106,53 & 23,45 \\
al. & & & & & & & & & & \\
$(2001)^{(3)}$ & & & & & & & & & & \\
\hline Borges & 2,64 & 3,17 & 22,99 & 4,14 & 1,28 & 1,67 & 15,74 & - & 69,05 & 48,80 \\
$(2006)^{(4)}$ & & & & & & & & & & \\
\hline
\end{tabular}

(1) Valores adaptados considerados ideais para a cultura do milho segundo Martinez et al. (1999).

(2) Resultados obtidos neste trabalho considerando os híbridos 30F53 e 30F53YH em condições de campo. Sete Lagoas, MG, 2014.

(3) Valores médios adaptados do acúmulo de nutrientes foliares aos 63 dias após a emergência para obter $90 \%$ da produção máxima de grãos de milho. Coimbra, MG, 2001.

(4) Valores médios adaptados do acúmulo de nutrientes foliares aos 65 dias após a emergência dos híbridos GNZ2004 e P30F33. UFLA, Lavras, MG, 2006.

boas condições nas quais a cultura foi implantada. Este nutriente é vital para a fotossíntese e a regulação osmótica das células vegetais (Taiz \& Zeiger, 2004).

Com relação ao magnésio, os teores acumulados estão abaixo do considerado ideal para a cultura segundo Martinez et al. (1999). Mas esses valores são similares aos obtidos por Borges (2006), que trabalhou com duas cultivares, sendo o $30 \mathrm{~F} 33$ da mesma empresa que as utilizadas no presente trabalho.

Neste trabalho, foi obtido valor médio do teor de $\mathrm{Zn}$ nas folhas de $12,50 \mathrm{mg} / \mathrm{kg}$, sendo esse valor abaixo do valor considerado ideal para a cultura do milho segundo Martinez et al. (1999) e também inferior aos valores encontrados por outros autores
(Tabela 6). Contudo, Rosolem \& Franco (2000) constataram que o sistema radicular do milho mostrouse pouco sensível à deficiência de $\mathrm{Zn}$, não havendo prejuízo ao crescimento com teores do nutriente da ordem de $7 \mathrm{mg} \mathrm{kg}^{-1}$ nas raízes e de $12 \mathrm{mg} \mathrm{kg}^{-1}$ na parte aérea.

O baixo acúmulo de $\mathrm{Zn}$ pode ter ocorrido devido às condições de $\mathrm{pH}$ do solo e às altas taxas de nitrogênio, pois, como já citado neste trabalho, solos com alta fertilidade e uso intenso de fertilizantes nitrogenados têm manifestado deficiência de Zn. Contudo, os totais acumulados não prejudicaram o desempenho do milho.

Os micronutrientes cobre, ferro e manganês 
apresentaram acúmulos dentro do considerado ideal para a cultura (tabela 6). Segundo Gallo \& Coelho (1963), o milho não é muito responsivo à adubação com micronutrientes. Seus teores nas folhas dependem da fertilidade do solo, do antagonismo e de outras relações de micronutrientes, além de diferenças pela adubação, enfatizando a necessidade de conhecimento desses problemas na utilização de dados da análise foliar.

Observou-se, com este trabalho, não haver uma mudança no padrão de acúmulo de nutrientes em plantas de milho nas cultivares analisadas, sendo as diferenças observadas na produção e nas quantidades acumuladas e/ou exportadas. Contudo, os tratamentos de sementes de milho analisados não proporcionaram incrementos neste padrão de acúmulo.

\section{Conclusões}

A cultivar $\mathrm{P} 30 \mathrm{~F} 53 \mathrm{YH}$ proporciona maior produtividade de grãos quando tratada com os produtos Azo Total ${ }^{\circledR}$, Stimulate ${ }^{\circledR}$ e Cellerate ${ }^{\circledR}$ nas condições de realização deste trabalho.

Os tratamentos de sementes de milho com os produtos comerciais Azo Total ${ }^{\circledR}$, Stimulate ${ }^{\circledR}$ e Cellerate $^{\circledR}$ não incrementam significativamente a produtividade de grãos.

Os produtos comerciais Azo Total ${ }^{\circledR}$, Stimulate $^{\circledR}$ e Cellerate ${ }^{\circledR}$ aplicados nas sementes não influenciam os teores foliares de nutrientes em plantas de milho.

\section{Agradecimentos}

À UFSJ, ao CNPMS e à Capes.

\section{Referências}

ASHRAF, M. A.; RASOOL, M.; MIRZA, S. M. Nitrogen fixation and indole acetic acid production potential of bacteria isolated from rhizosphere of sugarcane (Saccharum officinarum L.). Advances in Biological Research, v. 5, n. 6, p. 348-355, 2011.

ÁVILA, M. R.; BRACCINI, A. de L.; SCAPIM, C. A.; MARTORELli, D. T.; ALBRECHT, L. P.; FACIOLLI, F. S. Qualidade fisiológica e produtividade das sementes de milho tratadas com micronutrientes e cultivadas no período de safrinha. Acta Scientiae Agronomy, Maringá, v. 28, n. 4, p. 535-543, 2006. DOI: $10.4025 /$ actasciagron.v28i4.927.

BALBINOT JÚNIOR, A. A.; BACKES, R. L.; ALVES, A. C.; OGLIARI, J. B.; FONSECA, J. A. Contribuição de componentes de rendimento na produtividade de grãos em variedades de polinização aberta de milho. Revista Brasileira de Agrociência, Pelotas, v. 11, n. 2, p. 161-166, 2005.

BORGES, I. D. Marcha de absorção de nutriente e acumulo de matéria seca em milho. 2006. 132 p. Tese (Doutorado) - Universidade Federal de Lavras, Lavras.

CAVALLET, L. E.; PESSOA, A. C. S.; HELMICH, J. J.; HELMICH, P. R.; OST, C. F. Produtividade do milho em resposta à aplicação de nitrogênio e inoculação das sementes com Azospirillum spp. Revista Brasileira de Engenharia Agricola e Ambiental, Campina Grande, v. 4, n. 1, p. 129-132, 2000.

DOI: $10.1590 / \mathrm{S} 1415-43662000000100024$.

CERETTA, C. A.; PAVINATO, A.; PAVINATO, P. S.; MOREIRA, I. C. L.; GIROTTO, E.; TRENTIN, E. E. Micronutrientes na soja: produtividade e análise econômica. Ciência Rural, Santas Maria, v. 35, n. 3, p. 576-581, 2005. DOI: 10.1590/S0103-84782005000300013.

CRUZ, J. C.; PEREIRA FILHO, I. A.; GARCIA, J. C.; MIRANDA, R. A. de. Rentabilidade exige híbridos de milho de alta qualidade. Campo \& Negócios, Uberlândia, v. 11, n. 125, p. $18-20,2013$. 
DIDONET, A. D.; LIMA, A. S.; CANDATEN, A. A.; RODRIGUES, O. Realocação de nitrogênio e de biomassa para os grãos em trigo submetidos à inoculação de Azospirillum. Pesquisa Agropecuária Brasileira, Brasília, DF, v. 35, n. 2, p. 401-411, 2000.

DOI: 10.1590/S0100-204X2000000200019.

DOTTO, A. P.; LANNA, M. C.; STEINER, F.; FRANDOLOSO, J. F. Produtividade do milho em resposta à inoculação com Herbaspirillum seropedicae sob diferentes níveis de nitrogênio. Revista Brasileira de Ciências Agrárias, Recife, v. 5, n. 3, p. 376-382, 2010.

DOI: 10.5039/agraria.v5i3a898.

FERREIRA,A.C.B.;ARAÚJO,G.A.A.;PEREIRA,P.R.G.; CARDODO, A. A. Características agronômicas e nutricionais do milho adubado com nitrogênio, molibdênio e zinco. Scientia Agrícola, Piracicaba, v. 58, n. 1, p. 131-138, 2001. DOI: $10.1590 / \mathrm{S} 0103-90162001000100020$.

FERREIRA, D. F. Sisvar: a computer statistical analysis system. Ciência e Agrotecnologia, Lavras, v. 35, n. 6, p. 1039-1042, 2011. DOI: $10.1590 / \mathrm{S} 1413-70542011000600001$.

FERREIRA, L. A.; OLIVEIRA, J. A.; VON PINHO, E. V. R.; QUEIROZ, D. L. Bioestimulante e fertilizante associados ao tratamento de sementes de milho. Revista Brasileira de Sementes, Brasília, DF, v. 29, n. 2, p. 80-89, 2007. DOI: $10.1590 / \mathrm{S} 0101-31222007000200011$.

GALLO, J. R.; COELHO, F. A. S. Diagnose da nutrição nitrogenada do milho pela análise química das folhas. Bragantia, Campinas, v. 22, p. 537-548, 1963.

DOI: $10.1590 /$ S0006-87051963000100051.

HUERGO, L. F. Regulação do metabolismo do nitrogênio em Azospirillum brasilense. 2006. 170 p. Tese (Doutorado em Bioquímica) - Universidade Federal do Paraná, Curitiba.

HUNGRIA, M. Inoculação com Azospirillum brasilien$\boldsymbol{s e}$ : inovação em rendimento a baixo custo. Londrina: Embrapa Soja, 2011. 36 p. (Embrapa Soja. Documentos, 325).
HUNGRIA, M.; CAMPO. R. J.; SOUZA, E. M.; PEDROSA, F. O. Inoculation with selected strains of Azospirillum brasilense and A. lipoferum improves yields of maize and wheat in Brazil. Plant and Soil, The Hague, v. 331, n. 1/2, p. 413-425, 2010. DOI: $10.1007 / \mathrm{s} 11104-009-0262-0$.

LUCHESE, A. V.; GONÇALVES JÚNIOR, A. C.; LUCHESE, E. B.; BRACCINI, M. do C. L. Emergência e absorção de cobre por plantas de milho (Zea mays) em resposta ao tratamento de sementes com cobre. Ciência Rural, Santa Maria, v. 34, n. 6, p. 1949-1952, 2004. DOI: $10.1590 / \mathrm{S} 0103-84782004000600044$.

MARTINEZ, H. E. P.; CARVALHO, J. G. de C.; SOUZA, R. B. Diagnose foliar. In: RIBEIRO, A. C.; GUIMARÃES, P. T. G.; ALVARES V., V. H. (Ed.). Recomendações para o uso de corretivos e fertilizantes em Minas Gerais: $5^{\text {a }}$ aproximação. Viçosa, MG: Comissão de Fertilidade do Solo no Estado de Minas Gerais, 1999. p. 313-316.

QUADROS, P. D. de; ROESCH, L. F. W.; SILVA, P. R. F. da; VIEIRA, V. M.; ROEHRS, D. D.; CAMARGO, F. A. de O. Desempenho agronômico a campo de híbridos de milho inoculados com Azospirillum. Revista Ceres, Viçosa, MG, v. 61, n. 2, p. 209-218, 2014. DOI: $10.1590 /$ S0034-737X2014000200008.

REPKE, R. A.; CRUZ, S. J. S.; SILVA, C. J. da; FIGUEIREDO, P. G.; BICUDO, S. J. Eficiência da Azospirillum brasilense combinada com doses de nitrogênio no desenvolvimento de plantas de milho. Revista Brasileira de Milho e Sorgo, Sete Lagoas, v. 12, n. 3, p. 214-226, 2013. DOI: 10.18512/1980-6477/rbms.v12n3p214-226.

ROESCH, L. F. W.; OLIVARES, F. L.; PASSAGLIA, L. P. M.; SELBACH, P. A.; SÁ, E. L. S. de; CAMARGO, F. A. O. Characterization of diazotrophic bacteria associated with maize: effect of plant genotype, ontogeny and nitrogen-supply. World Journal of Microbiology \&Biotechnology, Dordrecht, v. 22, n. 9, p. 967-974, 2006.

DOI: $10.1007 / \mathrm{s} 11274-006-9142-4$.

ROSOLEM, C. A.; FRANCO, G. R. Translocação de zinco 
e crescimento radicular em milho. Revista Brasileira de Ciência do Solo, Campinas, v. 24, n. 4, p. 807-814, 2000. DOI: $10.1590 / \mathrm{S} 0100-06832000000400013$.

SANGOI, L.; SILVA, L. M. M. da; MOTA, M. R.; PANISON, F.; SCHMITT, A.; SOUZA, N. M. de; GIORDANI. W.; SCHENATTO, D. E. Desempenho agronômico do milho em razão do tratamento de sementes com Azospirillum sp. e da aplicação de doses de nitrogênio mineral. Revista Brasileira de Ciência do Solo, Campinas, v. 39, n. 4, p. 1141-1150, 2015. DOI: $10.1590 / 01000683$ rbcs20140736.

SANTOS, M. M. dos. Nitrogênio (15N) e atividade das enzimas redutase do nitrato e glutamina sintetase na cultura do milho em plantio direto. 2008. 44 p. Tese (Doutorado) - Universidade Federal de Viçosa, Viçosa, MG.

SHARMA, S.; ANEJA, M. K.; MAYER, J.; MUNCH, J. C.; SCHLOTER, M. Diversity of transcripts of nitrite reductase genes (nirK and nirS) in rhizospheres of grain legumes. Applied and Environmental Microbiology,
Washington, v. 71, n. 4, p. 2001-2007, 2005.

DOI: 10.1128/AEM.71.4.2001-2007.2005.

SILVA, D. M.; ANTONIOLLI, Z. I.; SEMINOTI, R. J. J.; VOSS, M. Bactérias diazotróficas nas folhas e colmos de plantas de arroz irrigado (Oryza sativa L.). Revista Brasileira de Agrociência, Pelotas, v. 13, n. 2, p. 181-187, 2007.

SILVA, T. T. de A.; VON PINHO, E. V. R.; CARDOSO, D. L.; FERREIRA, C. A.; ALVIM, P. O.; COSTA, A. A. F. Qualidade fisiológica de sementes de milho na presença de bioestimulantes. Ciência e Agrotecnologia, Lavras, v. 32, n. 3, p. 840-846, 2008.

DOI: $10.1590 / \mathrm{S} 1413-70542008000300021$.

TAIZ, L.; ZIEGER, E. Fisiologia vegetal. 3. ed. Porto Alegre: Artmed, 2004. 559 p. 